\title{
Cr(pyrazine)2(OSO2CH3)2: A two-dimensional coordination polymer with an antiferromagnetic ground state
}

Perlepe, Panagiota; Oyarzabal, Itziar; Pedersen, Kasper Steen; Negrier, Philippe; Mondieig, Denise; Rouzières, Mathieu; Hillard, Elizabeth A.; Wilhelm, Fabrice; Rogalev, Andrei; Suturina, Elizaveta A. Total number of authors: 12

Published in:

Polyhedron

Link to article, DOI:

10.1016/j.poly.2018.07.011

Publication date:

2018

Document Version

Peer reviewed version

Link back to DTU Orbit

Citation (APA):

Perlepe, P., Oyarzabal, I., Pedersen, K. S., Negrier, P., Mondieig, D., Rouzières, M., Hillard, E. A., Wilhelm, F., Rogalev, A., Suturina, E. A., Mathonière, C., \& Clérac, R. (2018). Cr(pyrazine)2(OSO2CH3)2: A two-dimensional coordination polymer with an antiferromagnetic ground state. Polyhedron, 153, 248-253. https://doi.org/10.1016/j.poly.2018.07.011

\section{General rights}

Copyright and moral rights for the publications made accessible in the public portal are retained by the authors and/or other copyright owners and it is a condition of accessing publications that users recognise and abide by the legal requirements associated with these rights.

- Users may download and print one copy of any publication from the public portal for the purpose of private study or research.

- You may not further distribute the material or use it for any profit-making activity or commercial gain

- You may freely distribute the URL identifying the publication in the public portal 


\section{Accepted Manuscript}

Cr(pyrazine $)_{2}\left(\mathrm{OSO}_{2} \mathrm{CH}_{3}\right)_{2}$ : A Two-Dimensional Coordination Polymer with an Antiferromagnetic Ground State

Panagiota Perlepe, Itziar Oyarzabal, Kasper S. Pedersen, Philippe Negrier, Denise Mondieig, Mathieu Rouzières, Elizabeth A. Hillard, Fabrice Wilhelm, Andrei Rogalev, Elizaveta A. Suturina, Corine Mathonière, Rodolphe Clérac

PII: S0277-5387(18)30398-X

DOI: https://doi.org/10.1016/j.poly.2018.07.011

Reference: $\quad$ POLY 13276

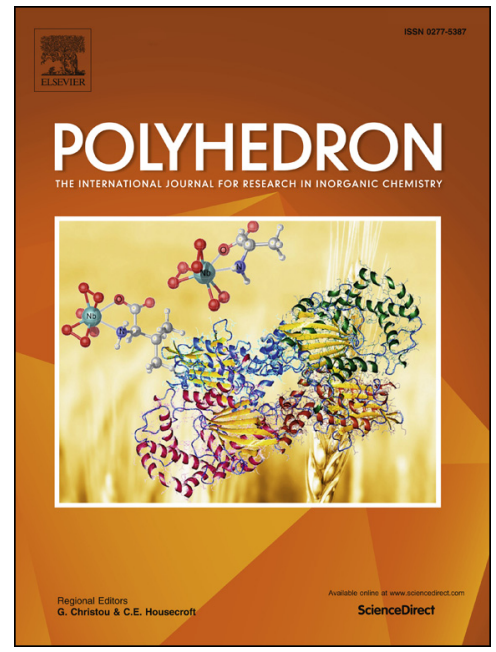

To appear in: $\quad$ Polyhedron

Received Date: $\quad 27$ April 2018

Revised Date: $\quad 9$ July 2018

Accepted Date: 10 July 2018

Please cite this article as: P. Perlepe, I. Oyarzabal, K.S. Pedersen, P. Negrier, D. Mondieig, M. Rouzières, E. A. Hillard, F. Wilhelm, A. Rogalev, E. A. Suturina, C. Mathonière, R. Clérac, $\mathrm{Cr}(\text { pyrazine })_{2}\left(\mathrm{OSO}_{2} \mathrm{CH}_{3}\right)_{2}$ : A TwoDimensional Coordination Polymer with an Antiferromagnetic Ground State, Polyhedron (2018), doi: https:// doi.org/10.1016/j.poly.2018.07.011

This is a PDF file of an unedited manuscript that has been accepted for publication. As a service to our customers we are providing this early version of the manuscript. The manuscript will undergo copyediting, typesetting, and review of the resulting proof before it is published in its final form. Please note that during the production process errors may be discovered which could affect the content, and all legal disclaimers that apply to the journal pertain. 


\section{$\mathrm{Cr}(\text { pyrazine })_{2}\left(\mathrm{OSO}_{2} \mathrm{CH}_{3}\right)_{2}$ : A Two-Dimensional Coordination Polymer with an Antiferromagnetic Ground State}

Panagiota Perlepe ${ }^{\mathrm{a}, \mathrm{b}, \mathrm{c}, \mathrm{d}}$, Itziar Oyarzabal*a,b ${ }^{\mathrm{a}, \mathrm{b}}$, Kasper S. Pedersen ${ }^{\mathrm{e}}$, Philippe Negrier ${ }^{\mathrm{f}, \mathrm{g}}$, Denise Mondieig $^{\mathrm{f}, \mathrm{g}}$, Mathieu Rouzières ${ }^{\mathrm{a}, \mathrm{b}}$, Elizabeth A. Hillard ${ }^{\mathrm{a}, \mathrm{b}}$, Fabrice Wilhelm ${ }^{\mathrm{h}}$, Andrei Rogalev $^{\mathrm{h}}$, Elizaveta A. Suturina ${ }^{\mathrm{i}, \mathrm{j}}$, Corine Mathonière ${ }^{\mathrm{*}, \mathrm{d}}$, Rodolphe Clérac*a,b

a) CNRS, CRPP, UMR 5031, F-33600 Pessac, France.

b) Univ. Bordeaux, CRPP, UMR 5031, F-33600 Pessac, France.

c) CNRS, ICMCB, UMR 5026, F-33600 Pessac, France.

d) Univ. Bordeaux, ICMCB, UMR 5026, F-33600 Pessac, France.

e) Department of Chemistry, Technical University of Denmark, DK-2800 Kgs. Lyngby, Denmark.

f) CNRS, LOMA, UMR 5798, F-33400 Talence, France.

g) Univ. Bordeaux, LOMA, UMR 5798, F-33400 Talence, France.

h) ESRF-The European Synchrotron, CS 40220, F-38043 Grenoble Cedex 9, France.

i) School of Chemistry, University of Southampton, Highfield Campus, SO17 1BJ, UK.

j) Novosibirsk State University, Pirogova 2, 660090 Novosibirsk, Russia

\section{Abstract}

A novel two-dimensional (2D) coordination polymer with the formula $\mathrm{Cr}$ (pyrazine $)_{2}\left(\mathrm{OSO}_{2} \mathrm{CH}_{3}\right)_{2}$ has been synthesized and characterized. Powder $\mathrm{X}$-ray diffraction data reveal that this material, which crystalizes in the Pnnm orthorhombic space group, is composed of rectangular grid layers with octahedral $\mathrm{CrN}_{4} \mathrm{O}_{2}$ nodes and pyrazine vertices. Since the redox-active pyrazine ligand can be reduced in the presence of transition metals, X-ray absorption spectroscopy and quantum chemical calculations were used to confirm the $+\mathrm{II}$ oxidation state of the $\mathrm{Cr}$ center. Magnetic susceptibility measurements indicate the presence of antiferromagnetic interactions between the chromium(II) centers through the neutral pyrazine and suggest an antiferromagnetic ordered state below $T_{\mathrm{N}} \approx 10 \mathrm{~K}$, which was confirmed by heat-capacity measurements.

*corresponding authors: Itziar Oyarzabal, Corine Mathonière, Rodolphe Clérac e-mail addresses: oyarzabal@crpp-bordeaux.cnrs.fr, corine.mathoniere@icmcb.cnrs.fr, clerac@crpp-bordeaux.cnrs.fr

Dedication: Dedicated to Professor Spyros Perlepes on the occasion of his 65th birthday.

Keywords: coordination polymers, pyrazine, magnetic order, X-ray spectroscopy 


\section{Introduction}

Transition metal pyrazine-based coordination polymers have been extensively studied, with many examples of various dimensionalities already reported in the literature [1]. Specific attention has been given to $\left\{\mathrm{M}^{\mathrm{II}}\right.$ (pyrazine) $\left.{ }_{2} \mathrm{~L}_{2-n} \mathrm{X}_{n}^{-}\right\} \mathrm{Y}_{2-n}^{-}(n=0,1$ or 2$)$ and $\left\{\mathrm{M}^{\mathrm{II}}(\text { pyrazine })_{2} \mathrm{X}^{n-}\right\} \mathrm{Y}_{2-n}^{-}(n=1$ or 2$)$ systems $(\mathrm{M}=$ metal ion, $\mathrm{L}=$ neutral coligand, $\mathrm{X}=$ anionic coligand, $\mathrm{Y}=$ counteranion), which all feature parallel sheets containing a periodic square or quasi-square array of metal ions linked by pyrazine ligands. The final dimensionality of these coordination compounds is conditioned by the denticity of the coligands (L or X); monodentate ligands lead to two-dimensional (2D) networks [2], while bidentate ligands result in three-dimensional (3D) systems [3]. In the latter case, the counterions $(\mathrm{Y})$ are located inside the voids and ensure the neutrality of the system when necessary. From the point of view of the magnetic properties, the exchange interactions between the metal centers through the pyrazine ligands are usually weak, often giving rise to a 3D ordered antiferromagnetic ground state at low temperatures $[2,3,4]$.

Very recently, our group reported the synthesis and characterization of an air-stable 2D coordination polymer based on chromium metal ions that belongs to this abovementioned family of compounds [5]. The reaction of $\mathrm{CrCl}_{2}$ with a large excess of pyrazine at $200{ }^{\circ} \mathrm{C}$ affords $\mathrm{Cr}$ (pyrazine) ${ }_{2} \mathrm{Cl}_{2}$ which incorporates $\mathrm{Cr}^{\mathrm{III}}$ metal ions and a singly reduced pyrazine scaffold, thanks to the redox non-innocence of the pyrazine ligand and the reducing ability of the chromium(II) used in the synthesis [6]. This unique electronic structure and the resulting strong degree of $\pi$-d conjugation in the $\mathrm{Cr}^{\mathrm{III}} /$ pyrazine layers induce an enormous $\mathrm{Cr}^{3+}$-radical exchange interaction (around $3000 \mathrm{~K}$ with the $-2 J$ convention) that stabilizes a $3 \mathrm{D}$ ferrimagnetic order at relatively high temperature $(55 \mathrm{~K})$. Concomitantly, the remarkable electronic delocalization within the chromium/pyrazine layer leads to a high electrical conductivity of $32 \mathrm{mS}$ $\mathrm{cm}^{-1}$ at room temperature, which constitutes one of the highest conductivity values reported so far for coordination solids [7,8]. This unique material, in which a ferrimagnetic order and high electrical conductivity coexist [5], encouraged us to develop an intense research activity in order to modulate and eventually improve the physical properties of these 2D materials. With the aim to study the effect of the axial ligands on the magnetic and electronic properties of analogous chromium/pyrazine 2D 
systems, we report herein the synthesis and characterization of $\mathrm{Cr}$ (pyrazine $)_{2}\left(\mathrm{OSO}_{2} \mathrm{CH}_{3}\right)_{2}$ for which the chloride coligands of $\mathrm{Cr}(\text { pyrazine })_{2} \mathrm{Cl}_{2}$ have been replaced by methanesulfonate anions.

\section{Experimental section}

\subsection{Materials and physical measurements}

All reactions were performed under a dry argon or nitrogen atmosphere using Schlenk or glovebox techniques. Acetonitrile was purified with an Innovative Technologies solvent-purification system. All chemicals were purchased from Sigma-Aldrich (chromium powder, 99.5\%, $\sim 100$ mesh and pyrazine, $\geq 99 \%$ ) or Alfa Aesar (methanesulfonic acid, $\geq 98 \%$ ) and used as received.

CHNS elemental analyses were performed by the Service d'Analyse Elémentaire of the University of Lorraine, Nancy. The FT-IR spectra were recorded in the range 600$4000 \mathrm{~cm}^{-1}$ on a Thermo Scientific Nicolet ${ }^{\mathrm{TM}} 6700$ ATR (attenuated total reflection) spectrometer equipped with a Smart iTR diamond window (Figure S2). Raman spectroscopic characterization was carried out on a Horiba Jobin Yvon Xplora microscope equipped with a cooled Andor CCD detector (Figure S3). X-ray absorption (XAS) spectra were obtained at the ID12 beamline of the European Synchrotron Radiation Facility (ESRF). The fundamental harmonic of an Apple-II type undulator was used for the experiments at the Cr K-edge. All XAS spectra were recorded using total fluorescence yield detection mode and were subsequently corrected for reabsorption effects. Thermogravimetric analysis (TGA) of $\mathrm{Cr}\left(\mathrm{OSO}_{2} \mathrm{CH}_{3}\right)_{2}\left(\mathrm{H}_{2} \mathrm{O}\right)_{4}$ was carried out under an argon flow at a rate of $5{ }^{\circ} \mathrm{C} / \mathrm{min}$ on a TA Q50 thermobalance (Figure S4).

Magnetic measurements were performed on a Quantum Design SQUID magnetometer MPMS-XL operating between 1.8 and $300 \mathrm{~K}$ for applied $d c$ fields ranging from -7 to 7 T. An $M$ vs $H$ measurement was carried out at $100 \mathrm{~K}$ to confirm the absence of ferromagnetic impurities. The measurements were performed on a microcrystalline sample $(12.90 \mathrm{mg})$ sealed in polypropylene bag (size and mass: $3 \times 0.5 \times 0.02 \mathrm{~cm} ; 27.6$ $\mathrm{mg}$ ). The magnetic data were corrected for the sample holder and intrinsic diamagnetic contributions of the sample. Heat capacity was measured on a manually pressed pellet of $\mathrm{Cr}$ (pyrazine $)_{2}\left(\mathrm{OSO}_{2} \mathrm{CH}_{3}\right)_{2}(7.0 \mathrm{mg})$ between 298 and $2 \mathrm{~K}$ by a thermal relaxation technique with a Quantum Design Physical Property Measurement System (PPMS-9) in 
zero- $d c$ field. A blank including a small amount of Apiezon $\mathrm{N}$ grease $(1.5 \mathrm{mg})$ used for thermal contact was measured prior to sample mounting and subtracted from the measured total heat capacity.

\subsection{Synthesis of anhydrous $\mathrm{Cr}\left(\mathrm{OSO}_{2} \mathrm{CH}_{3}\right)_{2}$}

A mixture of chromium powder $(2.0 \mathrm{~g}, 38 \mathrm{mmol})$ and methanesulfonic acid $(6.0 \mathrm{~g}, 62$ $\mathrm{mmol}$ ) in $7 \mathrm{~mL}$ of water was stirred under reflux overnight, to yield a bright blue solution. While still hot, the solution was filtered under argon to remove the unreacted $\mathrm{Cr}$ powder and allowed to cool to room temperature. The solvent was then removed under reduced pressure and the obtained powder was heated under dynamic vacuum at $180{ }^{\circ} \mathrm{C}$ for 7 hours. Yield: 55\%. Elemental analysis calc. for $\mathrm{C}_{2} \mathrm{H}_{6} \mathrm{CrO}_{6} \mathrm{~S}_{2}(242.19 \mathrm{~g}$ $\mathrm{mol}^{-1}$ ) C: $9.92 \%, \mathrm{H}: 2.50 \%$, S: $26.48 \%$; found C: $9.52 \%, \mathrm{H}: 2.42 \%$, S: $26.76 \%$. FT-IR $\left(\bar{v}, \mathrm{~cm}^{-1}\right):$ 3034(w), 2944(w), 1419(w), 1334(m), 1270(m), 1236(w), 1170(w), 1146(m), 1122(m), 1068(s), 981(m), 785(s).

\subsection{Synthesis of $\mathrm{Cr}(\text { pyrazine })_{2}\left(\mathrm{OSO}_{2} \mathrm{CH}_{3}\right)_{2}$}

Anhydrous $\mathrm{Cr}\left(\mathrm{OSO}_{2} \mathrm{CH}_{3}\right)_{2}(0.20 \mathrm{~g}, 0.83 \mathrm{mmol})$ and pyrazine $(1.0 \mathrm{~g}, 12.5 \mathrm{mmol})$ were placed inside a $30 \mathrm{~mL}$ Teflon-lined solvothermal reactor and allowed to react for 15 hours at $200{ }^{\circ} \mathrm{C}$ in an oven. The reactor was cooled to room temperature over about 2 hours and the brown microcrystalline product was washed with $20 \mathrm{~mL}$ of acetonitrile and dried in vacuo. Yield: $60-65 \%$. Elemental analysis calc. for $\mathrm{C}_{10} \mathrm{H}_{14} \mathrm{CrN}_{4} \mathrm{O}_{6} \mathrm{~S}_{2}$ (402.37 $\left.\mathrm{g} \mathrm{mol}^{-1}\right) \mathrm{C}: 29.85 \%, \mathrm{H}: 3.51 \%, \mathrm{~N}: 13.92 \%, \mathrm{~S}: 15.94 \%$; found C: $29.59 \%, \mathrm{H}$ : 3.49\%, N: 13.90\%, S: 16.09\%. FT-IR ( $\left.\bar{v}, \mathrm{~cm}^{-1}\right)$ : 3108(w), 3019(w), 2930(w), 1490(w), 1421(s), 1343(w), 1251(s), 1160(s), 1139(s), 1115(s), 1071(m), 1033(s), 837(m), 805(m), 775(s), 559(s). Raman $(\lambda=785 \mathrm{~nm})\left(\bar{v}, \mathrm{~cm}^{-1}\right): 671,708,785,872,1034,1053$, 1166, 1244, 1431, 1525.

\subsection{X-ray powder diffraction}

High-resolution X-ray powder diffraction measurements using the Debye-Scherrer geometry and transmission mode were performed with a horizontally mounted INEL cylindrical position sensitive detector (CPS-120) made of 4096 channels [9]. Monochromatic $\mathrm{Cu}-\mathrm{K} \alpha_{1}(\lambda=1.54056 \AA)$ radiation was selected by means of an 
asymmetrically focusing incident beam curved quartz monochromator. The generator power was set to $1.0 \mathrm{~kW}(40 \mathrm{kV}$ and $25 \mathrm{~mA})$. External calibration was performed by means of cubic phase NAC $\left(\mathrm{Na}_{2} \mathrm{Ca}_{2} \mathrm{Al}_{2} \mathrm{~F}_{14}\right)$ mixed with silver behenate to convert the channels into angles by means of cubic spline fittings, providing an angular step of $0.029^{\circ}(2 \theta)$ between $0^{\circ}$ and $120^{\circ}$. The powder sample was introduced at $297 \mathrm{~K}$ into a $0.5 \mathrm{~mm}$ diameter Lindemann glass capillary which was rotated around its longitudinal axes during data collection to prevent the effects of the preferred orientations. The acquisition time was 10 hours. Indexing of the X-ray powder diffraction pattern, Pawley refinement, structure solution by the rigid body direct space method using the $\mathrm{Cu}$ based isostructural compound as reference [10], and final Rietveld refinement were performed with the Materials Studio program [11]. Crystal data are summarized in Table S1 and the powder diffractogram can be found in the Supplementary Materials (Figure S1).

\subsection{Computational details}

Quintet, triplet and singlet states were computed for neutral molecular fragments, $\left.\{\mathrm{Cr} \text { (pyrazine })_{4}\left(\mathrm{OSO}_{2} \mathrm{CH}_{3}\right)_{2}\right\}$ and $\left.\{\mathrm{Cr} \text { (pyrazine })_{4} \mathrm{Cl}_{2}\right\}$, taken from the crystal structures (B3LYP/def2-TZVP) [12]. Exchange interactions between $\mathrm{Cr}(\mathrm{II})$ sites along the crystallographic $a$ - and $c$-axes were calculated using the broken-symmetry approach $[13,14]$. Ab initio ligand field analysis and calculation of $g$ - and $D$-tensors were done with the SOC-CASSCF(4,5)/def2-TZVP approach [15]. ORCA 4.0 was used for all calculations [16].

\section{Results and discussion}

Transition metal methanesulfonate salts are usually prepared through reactions between the corresponding metal oxides, carbonates and/or chlorides and methanesulfonic acid [17]. These reactions give $\mathrm{M}\left(\mathrm{OSO}_{2} \mathrm{CH}_{3}\right)_{2}\left(\mathrm{H}_{2} \mathrm{O}\right)_{4}$ complexes, where four water molecules occupy the equatorial plane and two axial methanesulfonate groups complete the octahedral coordination sphere [18]. Thermogravimetric analysis has shown that dehydration of these compounds occurs in two steps, each of them corresponding to the loss of two water molecules. The anhydrous metal methanesulfonate salts are generally stable over a wide temperature range before decomposition [19]. 
The $\mathrm{Cr}$ methanesulfonate analogue was obtained by the reaction of metallic $\mathrm{Cr}$ and methanesulfonic acid and isolated for the first time. Although single-crystal X-ray crystallographic analysis was not possible due to sensitivity to air and moisture, a variety of analytical techniques lead us to conclude that the formula of this methanesulfonate salt is indeed $\mathrm{Cr}\left(\mathrm{OSO}_{2} \mathrm{CH}_{3}\right)_{2}\left(\mathrm{H}_{2} \mathrm{O}\right)_{4}$. Infrared spectroscopy unambiguously reveals the presence of the sulfonate groups. The asymmetric and symmetric $\mathrm{SO}_{2}$ stretching vibrations appear in the $1270-1146 \mathrm{~cm}^{-1}$ region, and at $1068 \mathrm{~cm}^{-1}$, respectively, while the C-S stretching vibration manifests itself at $785 \mathrm{~cm}^{-1}$ (Figure S2). Dehydration of this compound occurs in two successive steps (Figure S4), each corresponding to the loss of two water molecules, as reported in the literature for other $3 d$ methanesulfonate salts. The eventual loss of a total of four water molecules at $140{ }^{\circ} \mathrm{C}$ confirms their initial presence in $\mathrm{Cr}\left(\mathrm{OSO}_{2} \mathrm{CH}_{3}\right)_{2}\left(\mathrm{H}_{2} \mathrm{O}\right)_{4}$.

The $\mathrm{Cr}$ (pyrazine $)_{2}\left(\mathrm{OSO}_{2} \mathrm{CH}_{3}\right)_{2}$ network was synthesized similarly to the $\mathrm{Cr}$ (pyrazine $)_{2} \mathrm{Cl}_{2}$ parent compound [5], by means of a solvothermal reaction of the dehydrated $\mathrm{Cr}^{\mathrm{II}} / \mathrm{methanesulfonate}$ salt and pyrazine (see experimental section). Importantly, the employment of anhydrous $\mathrm{Cr}\left(\mathrm{OSO}_{2} \mathrm{CH}_{3}\right)_{2}$ is crucial for the isolation of the final $2 \mathrm{D}$ compound as the reaction between the hydrated $\mathrm{Cr}^{\mathrm{II}}$ methanesulfonate and an excess of pyrazine does not yield the desired product.

\subsection{Crystal structure description of $\mathrm{Cr}(\text { pyrazine })_{2}\left(\mathrm{OSO}_{2} \mathrm{CH}_{3}\right)_{2}$}

The crystal structure of $\mathrm{Cr}(\text { pyrazine })_{2}\left(\mathrm{OSO}_{2} \mathrm{CH}_{3}\right)_{2}$ (Figures 1 and 2) was solved from the Rietveld refinement of the X-ray powder diffraction data, which shows that it crystallizes in the orthorhombic Pnnm space group (see Supplementary Materials; Table S1 and Figure S1). The compound consists of stacked layers, each of them being composed of an infinite rectangular array of chromium metal ions $(\mathrm{Cr} \cdots \mathrm{Cr}$ distances of 8.086(2) $\AA$ and 7.121(2) $\AA$ ) bridged by bidentate pyrazine ligands. The coordination environment around the $\mathrm{Cr}$ centers is completed by two $\mathrm{O}$ atoms belonging to monodentate methanesulfonate anions (Figure 2). The 2D networks are spaced by $6.67 \AA$ along the crystallographic $b$ axis, and are arranged in such a way that the $\mathrm{Cr}$ centers of one layer are positioned above the middle of the rectangle created by the $\mathrm{Cr}$ centers in the adjacent layer. All $\mathrm{Cr}$ ions are six-coordinate with a distorted octahedral geometry. The $\mathrm{Cr}$ equatorial plane, lying in the $a c$ crystallographic plane, contains two crystallographically independent pyrazine $\mathrm{N}$ atoms (N1 and $\mathrm{N} 2$ ), while the symmetry 
related $\mathrm{O}$ atoms $(\mathrm{O} 1)$ from the methanesulfonate ligands occupy the apical coordination sites (Figure 2). The Cr-N1 bond length of 2.162(1) $\AA$ is significantly shorter than the value of 2.631(2) $\AA$ between $\mathrm{Cr}-\mathrm{N} 2$, while the $\mathrm{Cr}-\mathrm{O} 1$ distance amounts to $1.996(6) \AA$. These metric parameters are consistent with a Jahn-Teller distortion at the $\mathrm{Cr}$ site, thus suggesting that the chromium ion is in a +2 -oxidation state.
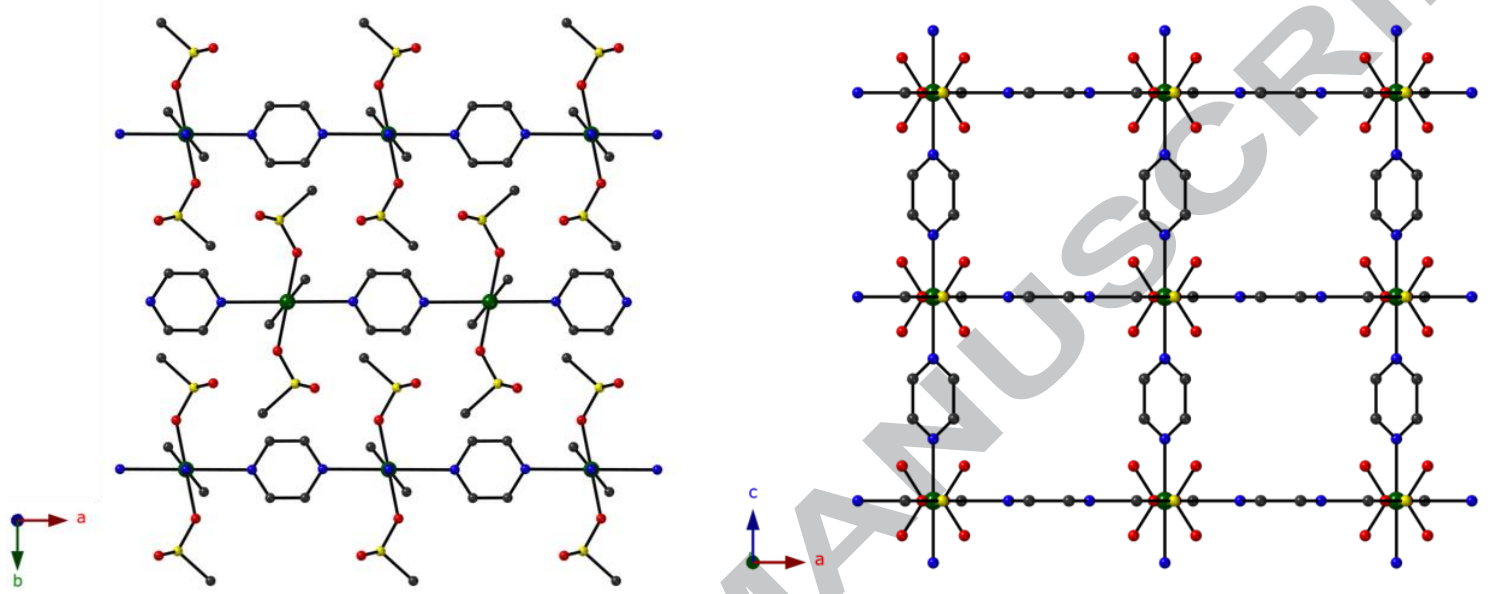

Figure 1. Crystal structure of $\mathrm{Cr}(\text { pyrazine })_{2}\left(\mathrm{OSO}_{2} \mathrm{CH}_{3}\right)_{2}$ : (left) side view of the layers stacking along the $b$ direction and (right) top view of a layer composing the structure in the $a c$ plane. Cr: dark green, N: blue, O: red, S: yellow, C: dark grey.

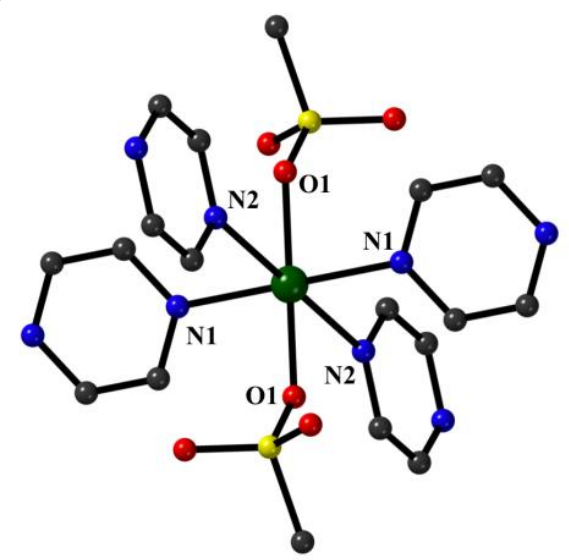

Figure 2. Local coordination environment around the $\mathrm{Cr}$ centre in $\mathrm{Cr}$ (pyrazine $)_{2}\left(\mathrm{OSO}_{2} \mathrm{CH}_{3}\right)_{2}$. Cr: dark green, $\mathrm{N}$ : blue, O: red, S: yellow, C: dark grey.

Similar bond distances were observed in the related $\mathrm{Cu}$ (pyrazine $)_{2}\left(\mathrm{OSO}_{2} \mathrm{CH}_{3}\right)_{2}$ layered structure [10], where a comparable distortion is observed for the $\mathrm{Cu}^{\mathrm{II}}$ centers. Also supporting the presence of $\mathrm{Cr}^{\mathrm{II}}$ centers in $\mathrm{Cr}(\text { pyrazine })_{2}\left(\mathrm{OSO}_{2} \mathrm{CH}_{3}\right)_{2}$, these results 
contrast considerably with the structural parameters found in the $\mathrm{Cr}^{\mathrm{III}}$ (pyrazine) ${ }_{2} \mathrm{Cl}_{2}$ analogue, in which (i) the $2 \mathrm{D}$ network is closer to a square lattice with similar $\mathrm{Cr} \cdots \mathrm{Cr}$ distances of 6.90351(4) and 6.97713(4) $\AA$ and $\mathrm{Cr}-\mathrm{N}$ bond lengths of 2.003(2) and 2.059 (2) $\AA$ and (ii) a significant axial distortion is also observed but perpendicularly to the $\mathrm{Cr} /$ pyrazine layer along the $\mathrm{Cl}-\mathrm{Cr}-\mathrm{Cl}$ axis with a $\mathrm{Cr}-\mathrm{Cl}$ bond length of 2.337(1) $\AA$ $[5]$.

\subsection{Electronic structure analysis}

DFT calculations capture a significant difference in the electronic structure of the molecular model fragment, $\left\{\mathrm{Cr}(\text { pyrazine })_{4}(\mathrm{~L})_{2}\right\}$, depending on the axial ligand, L, chloride [5] versus methanesulfonate anions shown in Figure 2. In the case of chloride [5], the triplet $\left(S_{\mathrm{T}}=1\right)$ ground state is about $19 \mathrm{kcal} \mathrm{mol}^{-1}(9560 \mathrm{~K})$ lower in energy than the quintet state and about $40 \mathrm{kcal} \mathrm{mol}^{-1}(20100 \mathrm{~K})$ lower than the singlet one. Mulliken population analysis shows the presence of 3.18 and 2.74 unpaired electrons on the $\mathrm{Cr}$ site, indicating a $\left\{\mathrm{Cr}^{\mathrm{III}}\left[(\text { pyrazine })_{4}\right]^{\circ} \mathrm{Cl}_{2}\right\}$ moiety with one unpaired electron smeared over the four pyrazine ligands for both the $S_{\mathrm{T}}=2$ and $S_{\mathrm{T}}=1$ states, as previously found [5]. In contrast, the axial methanesulfonate anions lead to an $S_{\mathrm{T}}=2$ ground state, which is $22 \mathrm{kcal} \mathrm{mol}^{-1}(11100 \mathrm{~K})$ lower than the triplet state and $70 \mathrm{kcal} \mathrm{mol}^{-1}(24500 \mathrm{~K})$ lower than the singlet one. The Mulliken population is estimated at 4.03 unpaired electrons on the $\mathrm{Cr}$ site in agreement with the presence of a $\left.\left\{\mathrm{Cr}^{\mathrm{II}} \text { (pyrazine) }\right)_{4}\left(\mathrm{OSO}_{2} \mathrm{CH}_{3}\right)_{2}\right\}$ moiety featuring a non-reduced pyrazine scaffold.

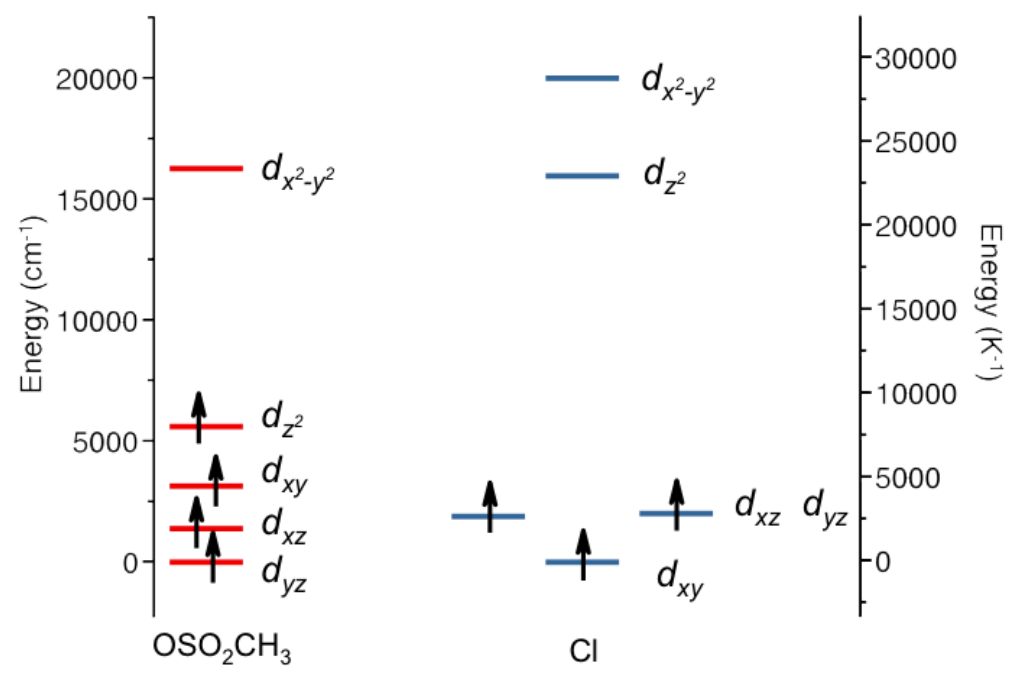

Figure 3. Splitting of $d$-orbitals computed by ab initio ligand field theory for $\left\{\mathrm{Cr}^{\mathrm{II}}(\text { pyrazine })_{4}\left(\mathrm{OSO}_{2} \mathrm{CH}_{3}\right)_{2}\right\}$ and $\left\{\mathrm{Cr}^{\mathrm{III}}\left[(\text { pyrazine })_{4}\right]^{*} \mathrm{Cl}_{2}\right\}$ fragments. 
$\mathrm{Ab}$ initio ligand field analysis shows that the overall splitting of the $d$-orbitals is significantly different and quite smaller in the presence of axial methanesulfonate ligands in comparison to the chloride case (Figure 3), as expected for the lower oxidation state and the Jahn-Teller distortion in the methanesulfonate case. The $\left.\left\{\mathrm{Cr}^{\mathrm{II}} \text { (pyrazine }\right)_{4}\left(\mathrm{OSO}_{2} \mathrm{CH}_{3}\right)_{2}\right\}$ moiety has the ligand field $z$-axis placed along the elongated Cr-N2 bonds, leading to a pronounced splitting of the $d_{x 2-y 2}$ and $d_{z 2}$ orbitals (Figures 3 and S7).

\subsection{Spectroscopic confirmation of the chromium oxidation state}

In the recently reported coordination polymer $\mathrm{Cr}$ (pyrazine) ${ }_{2} \mathrm{Cl}_{2}$ [5], the pyrazine ligands are partially reduced by the $\mathrm{Cr}^{\mathrm{II}}$ metal ions, resulting in the oxidation of the chromium centers in the final material. To explore this possible redox phenomenon in $\mathrm{Cr}$ (pyrazine $)_{2}\left(\mathrm{OSO}_{2} \mathrm{CH}_{3}\right)_{2}, \mathrm{X}$-ray absorption spectroscopy (XAS) measurements were performed at the $\mathrm{Cr}$ K-edge to confirm the +II-oxidation state of the chromium sites suggested by the X-ray structure analysis and DFT calculations (vide supra). XAS data were also collected for two reference compounds, trans-[Cr $\left.{ }^{\mathrm{II}} \mathrm{Cl}_{2}\left(\mathrm{NCNH}_{2}\right)_{4}\right](\mathbf{C r}(\mathbf{I I}))$ [20] and trans-[Cr ${ }^{\mathrm{III}}$ (pyridine) $\left.{ }_{4} \mathrm{Cl}_{2}\right]\left(\mathrm{ClO}_{4}\right) \cdot 1 / 4 \mathrm{H}_{2} \mathrm{O}(\mathbf{C r}$ (III) $)$ [5] in order to make a direct comparison of the XAS signature for $\mathrm{Cr}(\text { pyrazine })_{2}\left(\mathrm{OSO}_{2} \mathrm{CH}_{3}\right)_{2}$ and chromium-based complexes which have a well-established oxidation state. Systematically, the experimental data show intense rising edge features, corresponding to $1 \mathrm{~s} \rightarrow 4 \mathrm{p}$ transitions. The dipole-forbidden $1 \mathrm{~s} \rightarrow 3 \mathrm{~d}$ transitions (Figure 4 ) are also observed at the pre-edge but with a much weaker intensity. As previously discussed in the literature [5,21], the first pre-edge transition is a fingerprint of the $\mathrm{Cr}$ oxidation state independently of the ligand field. A close examination of the XAS results reveals important similarities between $\mathrm{Cr}$ (pyrazine $)_{2}\left(\mathrm{OSO}_{2} \mathrm{CH}_{3}\right)_{2}$ and $\mathbf{C r}(\mathbf{I I})$, with the energy of the $\mathrm{Cr}^{\mathrm{II}}$ pre-edge transition in $\mathbf{C r}(\mathbf{I I})$ being only $0.2 \mathrm{eV}$ higher in energy than in the present 2D compound. Therefore, both the crystallographic and spectroscopic characterization demonstrate the presence of $\mathrm{Cr}^{\mathrm{II}}$ centers in $\mathrm{Cr}(\text { pyrazine })_{2}\left(\mathrm{OSO}_{2} \mathrm{CH}_{3}\right)_{2}$. 


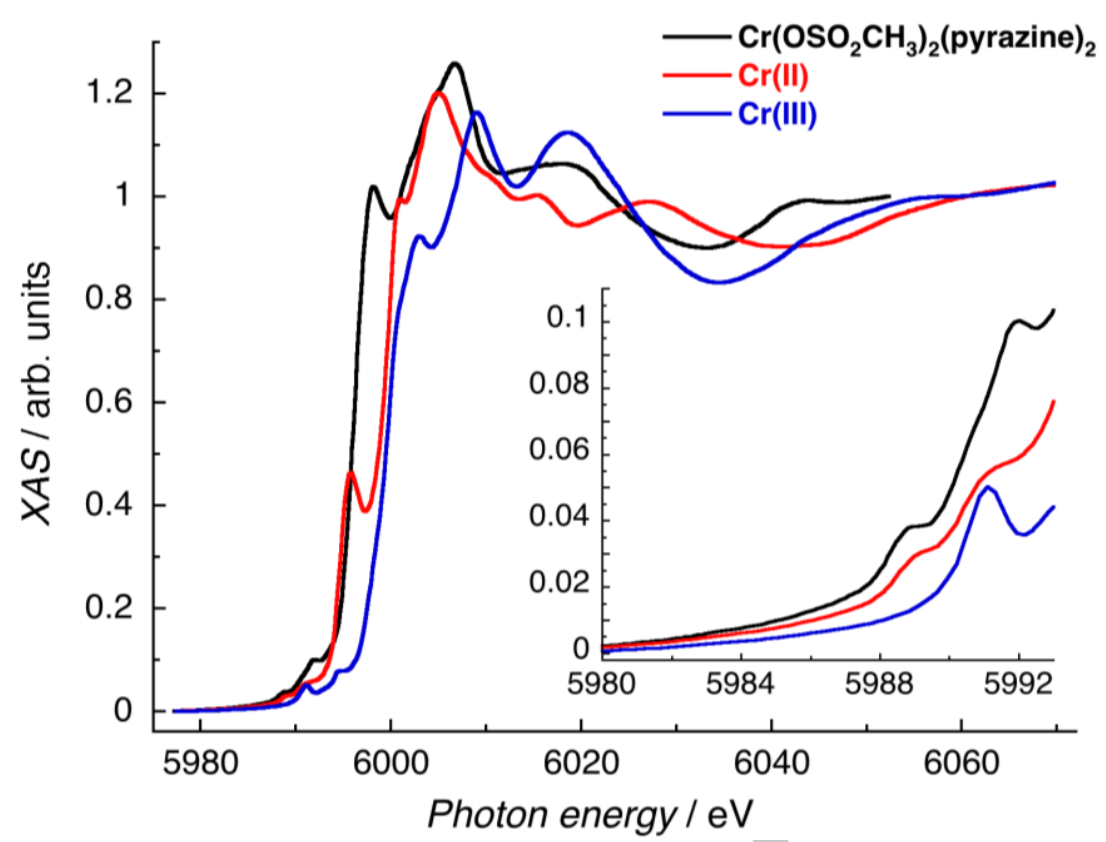

Figure 4. Normalized X-ray absorption spectroscopy (XAS) data at the Cr K-edge for $\mathrm{Cr}$ (pyrazine $)_{2}\left(\mathrm{OSO}_{2} \mathrm{CH}_{3}\right)_{2}$ at $295 \mathrm{~K}$ and reference compounds: $\mathbf{C r}$ (II) and $\mathbf{C r}$ (III) recorded both at $2.1 \mathrm{~K}$. Inset: Magnification of the $\mathrm{Cr} \mathrm{K}$ pre-edge region.

\subsection{Magnetic properties}

The temperature dependence of the magnetic susceptibility of $\mathrm{Cr}(\text { pyrazine })_{2}\left(\mathrm{OSO}_{2} \mathrm{CH}_{3}\right)_{2}$ was measured between 280 and $1.8 \mathrm{~K}$ under an applied $d c$ field of $0.1 \mathrm{~T}$ (Figure 5). The molar magnetic susceptibility-temperature product, $\chi T$, is $2.9 \mathrm{~cm}^{3} \mathrm{~K} \mathrm{~mol}^{-1}$ at $280 \mathrm{~K}$, in good agreement with the presence of a high-spin $S=2 \mathrm{Cr}^{\mathrm{II}}$ site $\left(C=3 \mathrm{~cm}^{3} \mathrm{~K} \mathrm{~mol}^{-1}\right.$ with $g=2$ ) as already concluded from theoretical, crystallographic and spectroscopic studies (vide supra). The $\chi T$ product steadily decreases with decreasing temperature and reaches a value of $0.08 \mathrm{~cm}^{3} \mathrm{~K} \mathrm{~mol}^{-1}$ at $1.85 \mathrm{~K}$. Such thermal behavior indicates the presence of predominant antiferromagnetic interactions between the magnetic chromium centers, which is also supported by a broad maximum of the $\chi$ vs. $T$ plot at $20 \mathrm{~K}$ (Figure 5). This magnetic feature is indeed commonly observed in pyrazine-based 2D quadratic-layered compounds in the presence of intra-layer antiferromagnetic interactions [2c]. The magnetic behavior of $\mathrm{Cr}(\text { pyrazine })_{2}\left(\mathrm{OSO}_{2} \mathrm{CH}_{3}\right)_{2}$ can also be discussed from the $\chi^{-1}$ vs $T$ plot (Figure S5) which shows a linear relationship in the 30$280 \mathrm{~K}$ temperature range consistent with a Curie-Weiss law $(g=2.11(5)$ and $\theta=-40 \mathrm{~K})$ and dominating antiferromagnetic interactions. 


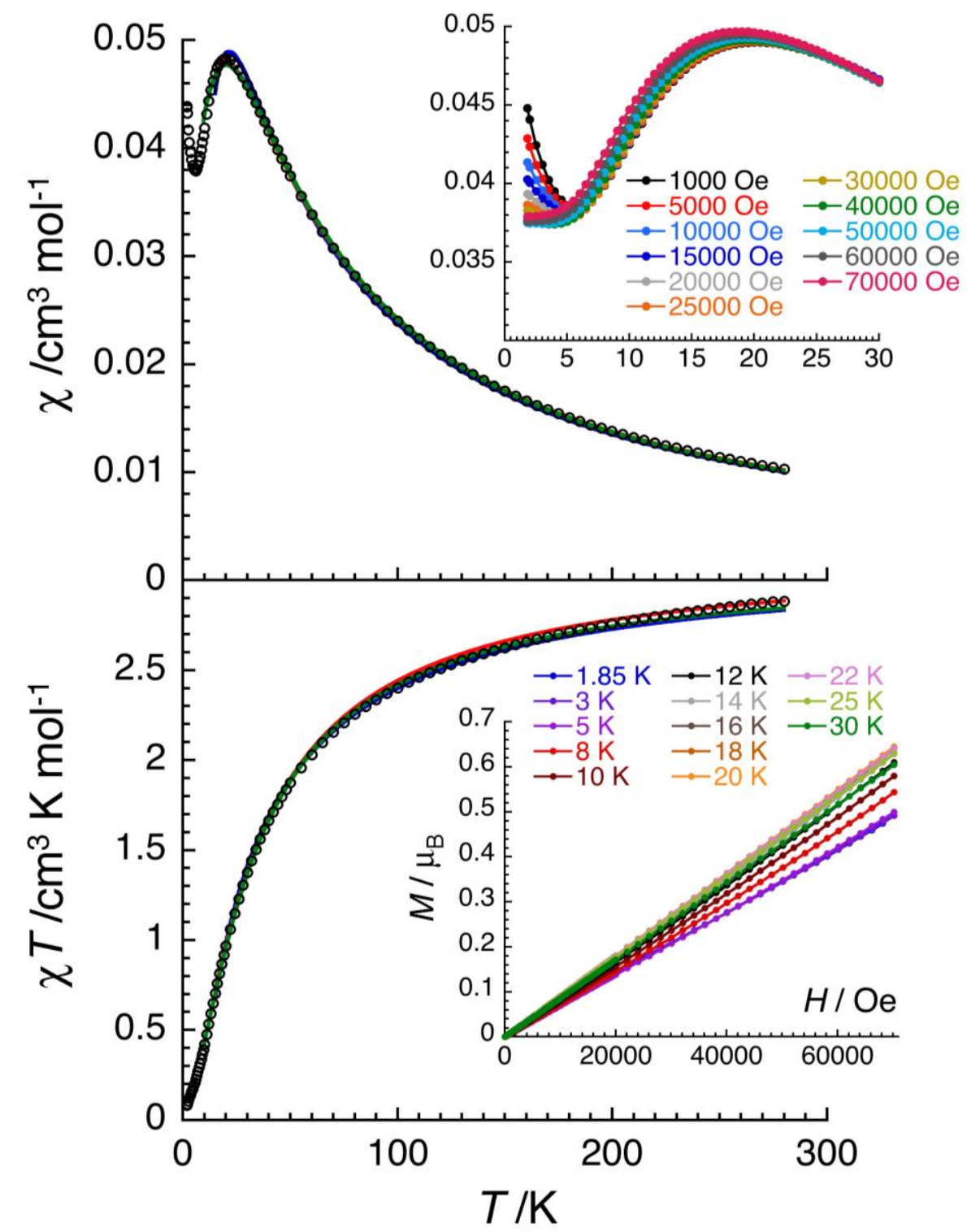

Figure 5. Temperature dependence of the magnetic susceptibility, $\chi$ (equal to $M / H$ per mole of $\mathrm{Cr}$ (pyrazine $)_{2}\left(\mathrm{OSO}_{2} \mathrm{CH}_{3}\right)_{2}$; top), and the $\chi T$ product (bottom) at $0.1 \mathrm{~T}$ (black circles are the experimental points). The solid red, blue and green lines are the best fits of the experimental data between 15 and $280 \mathrm{~K}$ to the Lines, Fisher and 1D-QMC models, respectively, as discussed in the main text. Insets: (top) Temperature dependence of the magnetic susceptibility at different applied field between 0.1 and $7 \mathrm{~T}$ for temperatures below $30 \mathrm{~K}$. (bottom) Field dependence of the magnetization up to $7 \mathrm{~T}$ at different temperatures between $1.85 \mathrm{~K}$ and $30 \mathrm{~K}$.

Considering the 2D arrangement of the magnetic chromium centers in this system, the susceptibility data were fitted to Lines' model, which is usually applied to describe the paramagnetic phase of 2D isotropic or weakly anisotropic quadratic-layer 
antiferromagnets (using the spin Hamiltonian: $\mathcal{H}=-2 J_{2 \mathrm{D}} \Sigma S_{\mathrm{i}} \cdot S_{\mathrm{j}}$ and the expression obtained from high-temperature series expansion techniques) [22]. This model assumes that the magnetic couplings, $J_{\mathrm{a}}$ and $J_{\mathrm{c}}$, in the two directions of the coordinating layer are equivalent and therefore, only an average $J_{2 \mathrm{D}}$ value is expected in the present case. The experimental data can be nicely reproduced by this approach down to $15 \mathrm{~K}$ (solid red lines in Figure 5), yielding $g=2.03(5)$ and an average intralayer coupling constant, $J_{2 \mathrm{D}} / k_{\mathrm{B}}=-1.73(5) \mathrm{K}$. As the $\mathrm{Cr} \cdots \mathrm{Cr}$ distances through the pyrazine ligands are indeed significantly different in the two crystallographic directions $(8.086(2) \AA$ versus 7.121(2) A along the $a$ and $c$ axes, respectively; vide supra), complementary Heisenberg $S=2$ spin chain models developed by Fisher [23] and Quantum Monte Carlo (QMC) [24] methods were also considered. With these approaches, the magnetic interaction, $J_{\mathrm{a}}$, between $\mathrm{Cr}$ centers along the $a$ direction is neglected, but the theory/experiment agreement (solid blue and green lines in Figure 5) is as satisfactory as the Lines' model above $15 \mathrm{~K}$, yielding $J_{1 \mathrm{D}} / k_{\mathrm{B}}=-3.26(5) \mathrm{K}(g=2.04(5))$ and $J_{1 \mathrm{D}} / k_{\mathrm{B}}=-3.11(5) \mathrm{K}(g=$ 2.03(5)) for the Fisher and QMC models, respectively. Of course, these 2D and 1D models, which involve different approximations, do not give the same theoretical value of the magnetic interaction through the pyrazine ligand. While the $2 \mathrm{D}$ model gives $J_{2 \mathrm{D}}$, an average estimation of $J_{\mathrm{a}}$ and $J_{\mathrm{c}}$, the $1 \mathrm{D}$ models overestimate the main interaction $J_{\mathrm{c}}$ in order to compensate for the absence of $J_{\mathrm{a}}$ in this approach. Therefore, $J_{2 \mathrm{D}}(-1.73 \mathrm{~K})$ and $J_{1 \mathrm{D}}(\approx-3.2 \mathrm{~K})$ should be considered as upper limits of the weakest and strongest couplings, most likely $J_{\mathrm{a}}$ and $J_{\mathrm{c}}$, in $\mathrm{Cr}$ (pyrazine $)_{2}\left(\mathrm{OSO}_{2} \mathrm{CH}_{3}\right)_{2}$. Interestingly, DFT calculations preferentially support the above 1D models, showing that the exchange interaction along the $a$-axis should be much smaller than along the $c$-axis with the following calculated values: $J_{\mathrm{a}} / k_{\mathrm{B}}=-0.01 \mathrm{~K}$ and $J_{\mathrm{c}} / k_{\mathrm{B}}=-5 \mathrm{~K}$. It is worth mentioning that CASSCF calculations allow also an estimation of the local $\mathrm{Cr}^{\mathrm{II}} g$-tensor $[1.96,1.99$, 1.99], its magnetic anisotropy parameters $D / k_{\mathrm{B}}=-3 \mathrm{~K}$ and $E / D=0.07$ (using the following Hamiltonian: $\left.\mathcal{H}_{\mathrm{A}}=D S_{\mathrm{Cr}, \mathrm{z}}{ }^{2}+E\left(S_{\mathrm{Cr}, \mathrm{x}}{ }^{2}-S_{\mathrm{Cr}, \mathrm{y}}{ }^{2}\right)\right)$. Due to the magnitude of the local anisotropy, its effects are not expected to influence the magnetic susceptibility above 15 $\mathrm{K}$.

Below $15 \mathrm{~K}$, the magnetic susceptibility becomes significantly field dependent, as shown in the inset of the Figure 5 top part, and the magnetization does not reach the expected $4 \mu_{\mathrm{B}}$ saturation value at $1.85 \mathrm{~K}$ and $7 \mathrm{~T}$ (inset of the Figure 5 bottom part). These features, as well as the non-strictly linear $M$ vs $H$ data, suggest a possible 
magnetic phase transition below $15 \mathrm{~K}$ toward a three-dimensional antiferromagnetic state.

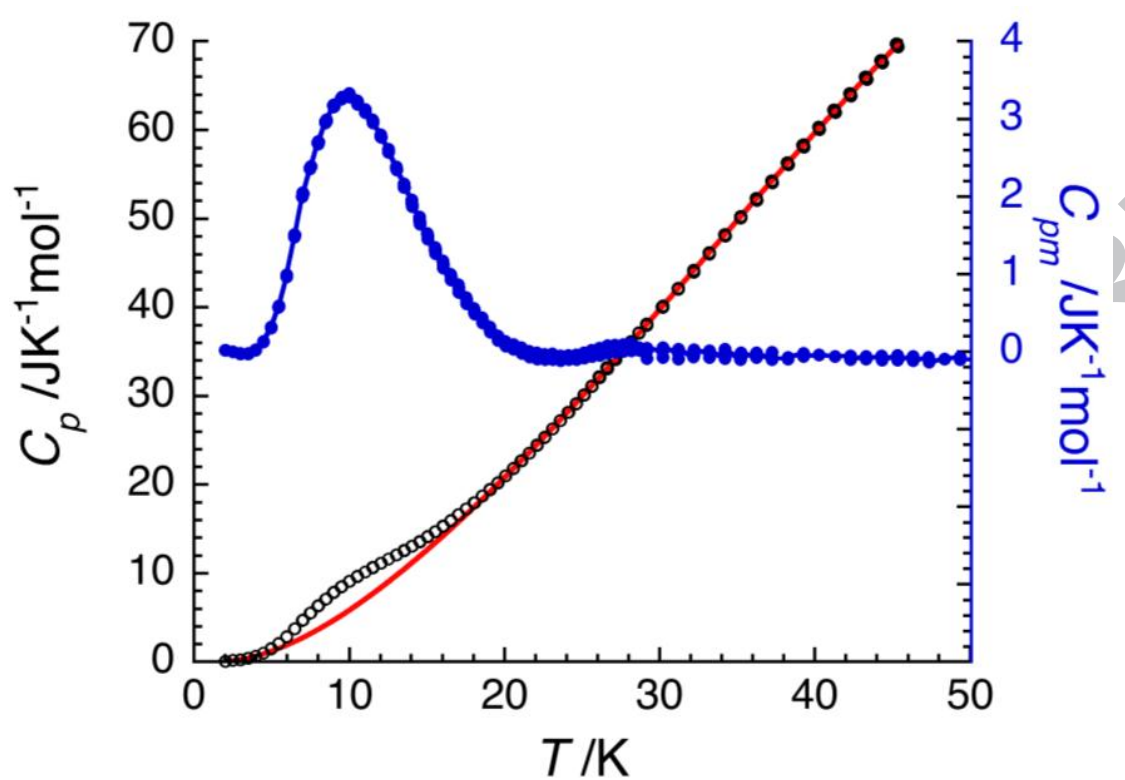

Figure 6. Black circles: temperature dependence of the heat capacity, $C_{\mathrm{p}}$, per mole of $\mathrm{Cr}$ (pyrazine $)_{2}\left(\mathrm{OSO}_{2} \mathrm{CH}_{3}\right)_{2}$ measured on a microcrystalline sample under zero-applied field. The red solid line corresponds to the empirical polynomial (at the $6^{\text {th }}$ order) baseline used to determine the non-magnetic background of the heat capacity $\left(C_{\text {background }}\right)$. Blue dots: Temperature dependence of the magnetic component $\left(C_{\mathrm{pm}}\right)$ of the heat capacity deduced from $C_{\mathrm{p}}-C_{\text {background. }}$

In order to probe a possible magnetic phase transition below $15 \mathrm{~K}$, heat capacity measurements were performed on $\mathrm{Cr}(\text { pyrazine })_{2}\left(\mathrm{OSO}_{2} \mathrm{CH}_{3}\right)_{2}$. As shown in Figure 6, a reproducible broad feature is observed in the 5-15 $\mathrm{K}$ temperature range, confirming the presence of an ordered magnetic ground state. The broadness of this feature could result from the thermal excitations among $S=2$ microspin states (Schottky anomaly) [25] and/or from large spin correlations always present in low dimensional systems above the transition temperature [26]. In order to further analyze these calorimetric measurements, the magnetic component $\left(C_{\mathrm{pm}}\right.$, Figure 6$)$ of the heat capacity was separated from the baseline modeled to an empirical polynomial expression (red line in Figure 6). This non-magnetic background, mainly composed of the lattice contribution, was then subtracted from the measured heat capacity data $\left(C_{\mathrm{p}}\right)$ and the resulting magnetic component of $C_{\mathrm{p}}\left(C_{\mathrm{pm}}\right)$ was plotted as shown in Figure 6 (blue dots). A relatively broad magnetic peak with a maximum centered at $9.7 \mathrm{~K}$ is clearly detected. 
The integration of $C_{\mathrm{pm}} / T$ in the 2-30 K temperature range leads an associated magnetic entropy $\left(S_{\mathrm{m}}\right)$, which reaches a saturation value of $2.7 \mathrm{~J} \mathrm{~K}^{-1} \mathrm{~mol}^{-1}$ (Figure S5). This estimation is lower than the calculated entropy from the simple $R \ln (2 S+1)$ relation (13.4 $\mathrm{J} \mathrm{K}^{-1} \mathrm{~mol}^{-1}$ ). This discrepancy is not surprising considering the large entropy loss above the transition temperature due to the presence of short range correlations always present in low dimensional magnetic systems [26]. The combined heat capacity and magnetic measurements reveal unambiguously the occurrence of long-range antiferromagnetic order in $\mathrm{Cr}(\text { pyrazine })_{2}\left(\mathrm{OSO}_{2} \mathrm{CH}_{3}\right)_{2}$, with a Néel temperature around $10 \mathrm{~K}$.

\section{Conclusions}

A novel Cr/pyrazine-based 2D coordination network has been synthesized by using $\mathrm{Cr}\left(\mathrm{OSO}_{2} \mathrm{CH}_{3}\right)_{2}$, a precursor salt reported here for the first time. The structure of this coordination polymer, as established from X-ray powder diffraction data, shows that this solid consists of neutral $\mathrm{Cr}(\text { pyrazine })_{2}\left(\mathrm{OSO}_{2} \mathrm{CH}_{3}\right)_{2}$ layers containing an array of chromium metal ions bridged by bidentate pyrazine ligands and coordinated to methanesulfonate anions in their apical positions. As also supported by quantum chemical calculations, crystallographic, spectroscopic and magnetic characterization demonstrate unequivocally the presence of high-spin $\mathrm{Cr}^{\mathrm{II}}$ centers which contrast with the $\mathrm{Cr}$ (pyrazine) ${ }_{2} \mathrm{Cl}_{2}$ analogue which incorporates $\mathrm{Cr}^{\mathrm{III}}$ metal ions and a singly reduced pyrazine scaffold [5]. The redox process involving the oxidation of $\mathrm{Cr}^{\mathrm{II}}$ in $\mathrm{Cr}^{\mathrm{III}}$ and the reduction of one pyrazine in $\mathrm{Cr}$ (pyrazine $)_{2} \mathrm{Cl}_{2}$ is clearly disabled in $\mathrm{Cr}$ (pyrazine $)_{2}\left(\mathrm{OSO}_{2} \mathrm{CH}_{3}\right)_{2}$, likely due to the change of the redox potential at the $\mathrm{Cr}$ site induced by the substitution of chloride by methylsulfonate. The impact of the presence or absence of this redox process on the physical properties is colossal. While a high electrical conductivity $\left(32 \mathrm{mS} \mathrm{cm}^{-1}\right)$ and an ordered ferrimagnetic phase $(<55 \mathrm{~K})$ are observed in $\mathrm{Cr}$ (pyrazine) ${ }_{2} \mathrm{Cl}_{2}$, the present material is an antiferromagnet below $10 \mathrm{~K}$ and exhibits a gigaohm resistivity. This work clearly highlights that the activation of the redox process in these $2 \mathrm{D}$ pyrazine coordination networks is the key parameter in the design of high $T_{\mathrm{C}}$ magnets possessing high electrical conductivity.

\section{Appendix A. Supplementary data}


CCDC 1836082 contains the supplementary crystallographic data for $\mathrm{Cr}$ (pyrazine $)_{2}\left(\mathrm{OSO}_{2} \mathrm{CH}_{3}\right)_{2}$. These data can be obtained free of charge via http://www.ccdc.cam.ac.uk/conts/retrieving.html, or from the Cambridge Crystallographic Data Centre, 12 Union Road, Cambridge CB2 1EZ, UK; fax: (+44) 1223-336-033; or e-mail: deposit@ccdc.cam.ac.uk.

\section{Acknowledgements}

This work was supported by the University of Bordeaux, the Région Nouvelle Aquitaine, the Centre National de la Recherche Scientifique (CNRS) and the Marie Sklodowska-Curie grant 745696 ETSMM (Postdoctoral fellowship for I.O.). The authors thank the GdR MCM-2 (Magnétisme et Commutation Moléculaires) and the MOLSPIN COST action CA15128. E.A.S. acknowledges financial support from the Russian Science Foundation (Project 16-13-10155), EPSRC (EP/N006895/1), the Supercomputer Center of Novosibirsk State University and the IRIDIS High Performance Computing Facility. X. Ma, A. Hen, M. Platunov, E. Lebraud and S. Exiga are thanked for helpful discussions and experimental assistance.

\section{References}

[1] (a) A. B. P. Lever, J. Lewis, R. S. Nyholm, J. Chem. Soc. (1962) 1235-1246; (b) A. B. P. Lever, J. Lewis, R. S. Nyholm, J. Chem. Soc. (1963) 5042-5048; (c) M. Goldstein, F. B. Taylor, W. D. Unsworth, J. Chem. Soc., Dalton Trans. (1972) 418-422; (d) K. Travis Holman, H. H. Hammud, S. Isber, M. Tabbal, Polyhedron 24 (2005) 221-228; (e) T. Otieno, A. M. Gipson, S. Parkin, J. Chem. Crystallogr. 32 (2002) 81-85. (f) L. Carlucci, G. Ciani, D. M. Proserpio, A. Sironi, J. Am. Chem. Soc. 117 (1995) 45624569. (g) J. Liu, P. A. Goddard, J. Singleton, J. Brambleby, F. Foronda, J. S. Möller, Y. Kohama, S. Ghannadzadeh, A. Ardavan, S. J. Blundell, T. Lancaster, F. Xiao, R. C. Williams, F. L. Pratt, P. J. Baker, K. Wierschem, S. H. Lapidus, K. H. Stone, P. W. Stephens, J. Bendix, T. J. Woods, K. E. Carreiro, H. E. Tran, C. J. Villa, J. L. Manson, Inorg. Chem. 55 (2016), 3515-3529.

[2] (a) E. A. de Campos, N. J. O. Silva, F.-N. Shi, J. Rocha, CrystEngComm 16 (2014) 10439-10444; (b) M. Wriedt, C. Nather, Z. Anorg. Allg. Chem. 637 (2011) 666-671; (c) 
F. M. Woodward, P. J. Gibson, G. B. Jameson, C. P. Landee, M. M. Turnbull, R. D. Willett, Inorg. Chem. 46 (2007) 4256-4266.

[3] (a) J. L. Manson, S. H. Lapidus, P. W. Stephens, P. K. Peterson, K. E. Carreiro, H. I. Southerland, T. Lancaster, S. J. Blundell, A. J. Steele, P. A. Goddard, F. L. Pratt, J. Singleton, Y. Kohama, R. D. McDonald, R. E. Del Sesto, N. A. Smith, J. Bendix, S. A. Zvyagin, J. Kang, C. Lee, M.-H. Whangbo, V. S. Zapf, A. Plonczak, Inorg. Chem. 50 (2011) 5990-6009; (b) J. L. Manson, J. A. Schlueter, K. A. Funk, H. I. Southerland, B. Twamley, T. Lancaster, S. J. Blundell, P. J. Baker, F. L. Pratt, J. Singleton, R. D. McDonald, P. A. Goddard, P. Sengupta, C. D. Batista, L. Ding, C. Lee, M.-H. Whangbo, I. Franke, S. Cox, C. Baines, D. Trial, J. Am. Chem. Soc. 131 (2009) 67336747; (c) T. Liu, Y.-H. Chen, Y.-J. Zhang, Z.-M. Wang, S. Gao, Inorg. Chem. 45 (2006) 9148-9150.

[4] M. Kubus, A. Lanza, R. Scatena, L. H. R. Dos Santos, B. Wehinger, N. Casati, C. Fiolka, L. Keller, P. Macchi, C. Rüegg, K. W. Krämer, Inorg. Chem. 57 (2018) 49344943.

[5] K. S. Pedersen, P. Perlepe, M. L. Aubrey, D. N. Woodruff, S. E. Reyes-Lillo, A. Reinholdt, L. Voigt, Z. Li, K. Borup, M. Rouzières, D. Samohvalov, F. Wilhelm, A. Rogalev, J. B. Neaton, J. R. Long, R. Clérac, Nat. Chem. (2018) DOI: 10.1038/s41557018-0107-7.

[6] (a) T. G. Dunne, J. K. Hurst, Inorg. Chem. 19 (1980) 1152-1157; (b) J. Swartz, F. C. Anson, Inorg. Chem. 20 (1981) 2250-2257.

[7] G. Givaja, P. Amo-Ochoa, C. J. Gómez-García, F. Zamora, Chem. Soc. Rev. 41 (2012) 115-147.

[8] L. Sun, M. G. Campbell, M. Dincă, Angew. Chem. Int. Ed. 55 (2016) 3566-3579.

[9] J. Ballon, V. Comparat, J. Pouxe, Nucl. Instrum. Methods 217 (1983) 213-216.

[10] J. S. Haynes, S. J. Rettig, J. R. Sams, R. C. Thompson, J. Trotter, Can. J. Chem. 65 (1987) 420-426.

[11] M.S. Modeling, Materials Studio, version 5.5, http://accelrys.com/products/collaborative-science/biovia-materials-studio.

[12] F. Weigend, R. Ahlrichs, Phys. Chem. Chem. Phys. 7 (2005) 3297-3305.

[13] K. Yamaguchi, Y. Takahara, T. Fueno in: V.H. Smith (Ed.) Applied Quantum Chemistry; Reidel, Dordrecht (1986), pp 155. 
[14] T. Soda, Y. Kitagawa, T. Onishi, Y. Takano, Y. Shigeta, H. Nagao, Y. Yoshioka, K. Yamaguchi, Chem. Phys. Lett. 319 (2000) 223-230.

[15] M. Atanasov, D. Aravena, E. Suturina, B. Eckhard, D. Maganas, F. Neese, Coord. Chem. Rev. 289 (2015) 177-214.

[16] F. Neese, The ORCA program system, Wiley Interdiscip. Rev.: Comput. Mol. Sci. 2 (2012) 73-78.

[17] (a) A. Ramírez, M. L. Gómez, A. Guerrero, Thermochimica Acta 124 (1988) 9-16.

(b) N. C. Johnson, J. T. Turk, W. E. Bull, Inorganic Chim. Acta 25 (1977) 235-239. (c) J. S. Haynes, J. R. Sams, R. C. Thompson, Can. J. Chem. 59 (1981) 669-678.

[18] (a) F. Charbonnier, R. Faure, H. Loiseleur, Acta Cryst. B33 (1977) 1845-1848. (b)

F. Charbonnier, R. Faure, H. Loiseleur, J. Appl. Crys. 8 (1975) 493-494.

[19] (a) M. Wang, H. Jiang, Z. C. Wang, J. Therm. Anal. Calorim. 85 (2006) 751-754.

(b) M. Wang, Z. G. Song, H. Jiang, H. Gong, J. Therm. Anal. Calorim. 98 (2009) 801806.

[20] X. Tang, M. Speldrich, A. L. Tchougréeff, R. Dronskowksi, Z. Naturforsch. 67b (2012) 1205-1211.

[21] C. C. Scarborough, S. Sproules, C. J. Doonan, K. S. Hagen, T. Weyhermüller, K. Wieghardt, Inorg. Chem. 51 (2012) 6969-6982.

[22] M. E. Lines, J. Phys. Chem. Solids 31 (1970) 101-116.

[23] M. E. Fisher, Am. J. Phys 32 (1964) 343-346.

[24] J. M. Law, H. Benner, R. K. Kremer, J. Phys.: Condens. Matter. 25 (2013) 065601.

[25] M. Sorai, M. Nakano, Y. Miyazaki, Chem. Rev. 106 (2006) 976-1031.

[26] E. Čižmár, O. N. Risset, T. Wang, M. Botko, A. R. Ahir, M. J. Andrus, J.-H. Park, K. A. Abboud, D. R. Talham, M. W. Meisel, S. E. Brown, J. Phys.: Condens. Matter 28 (2016) 236003. 

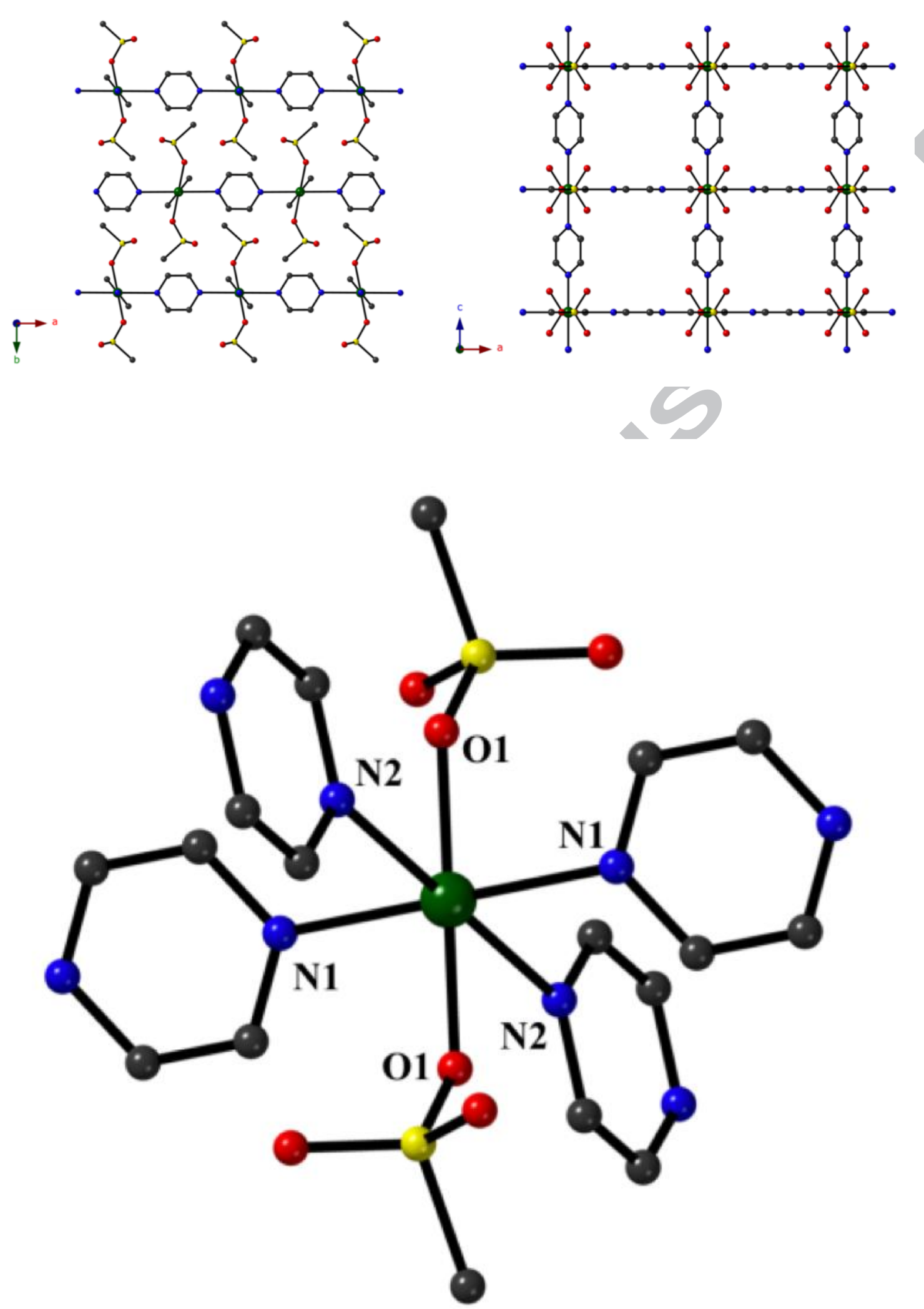

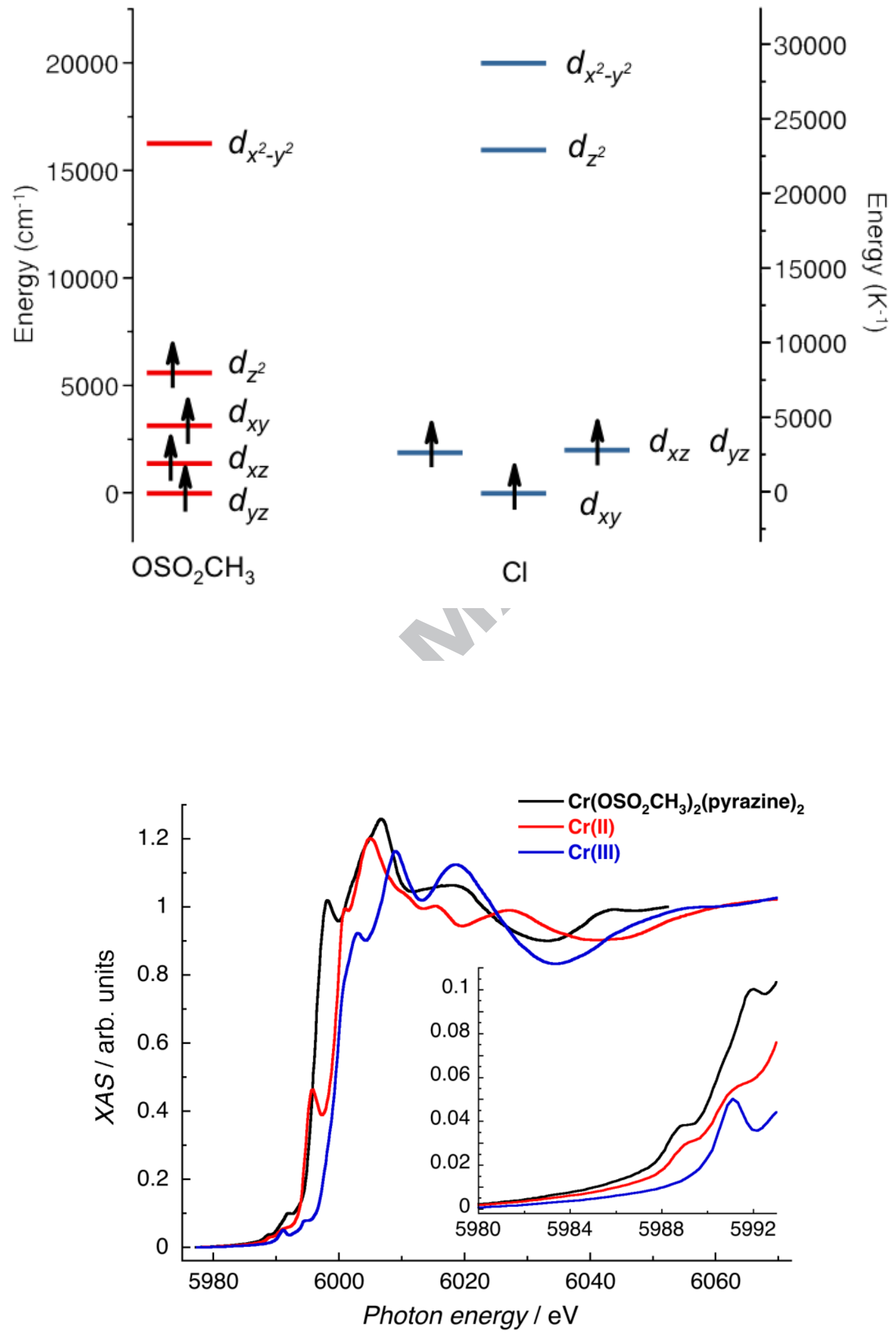


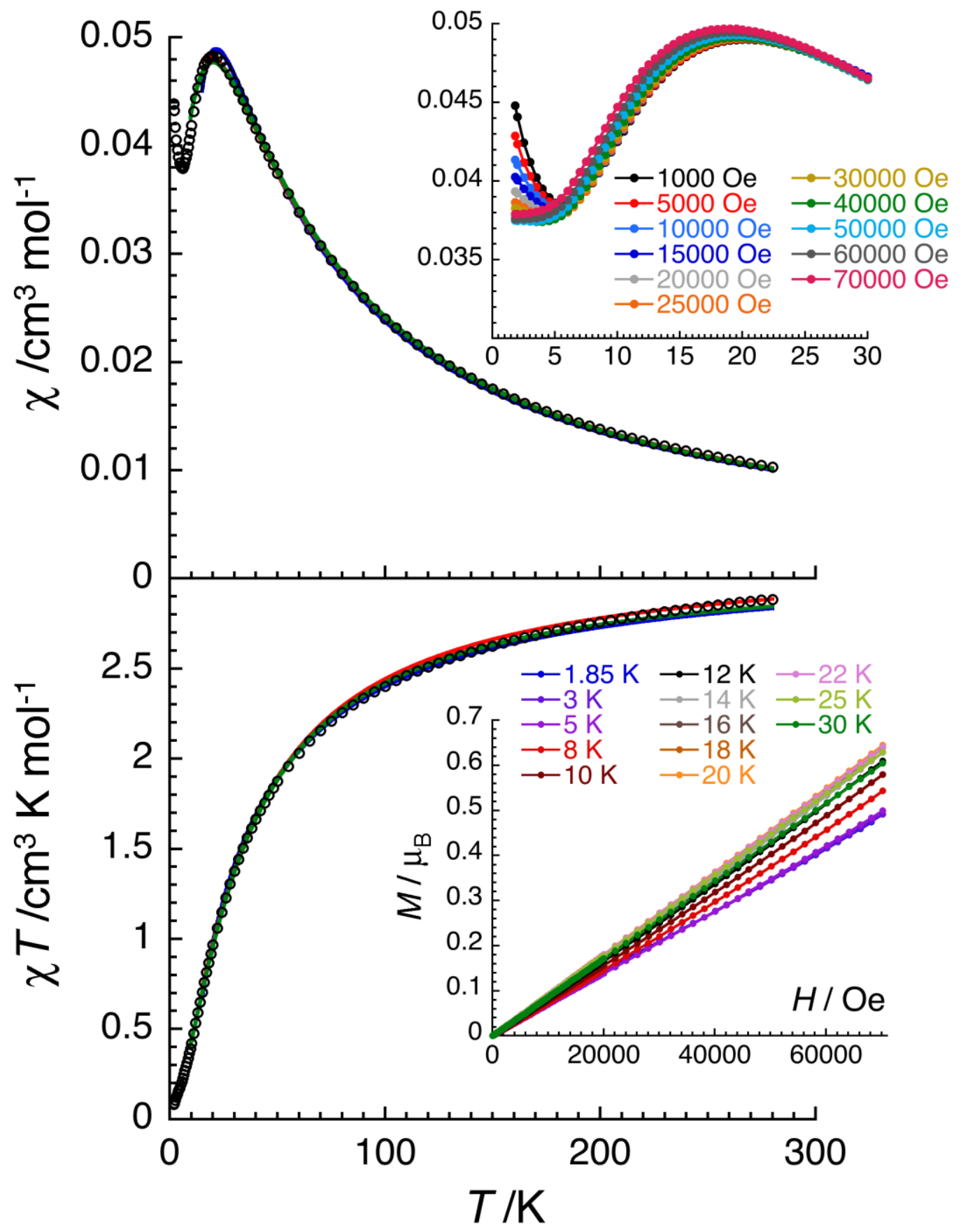




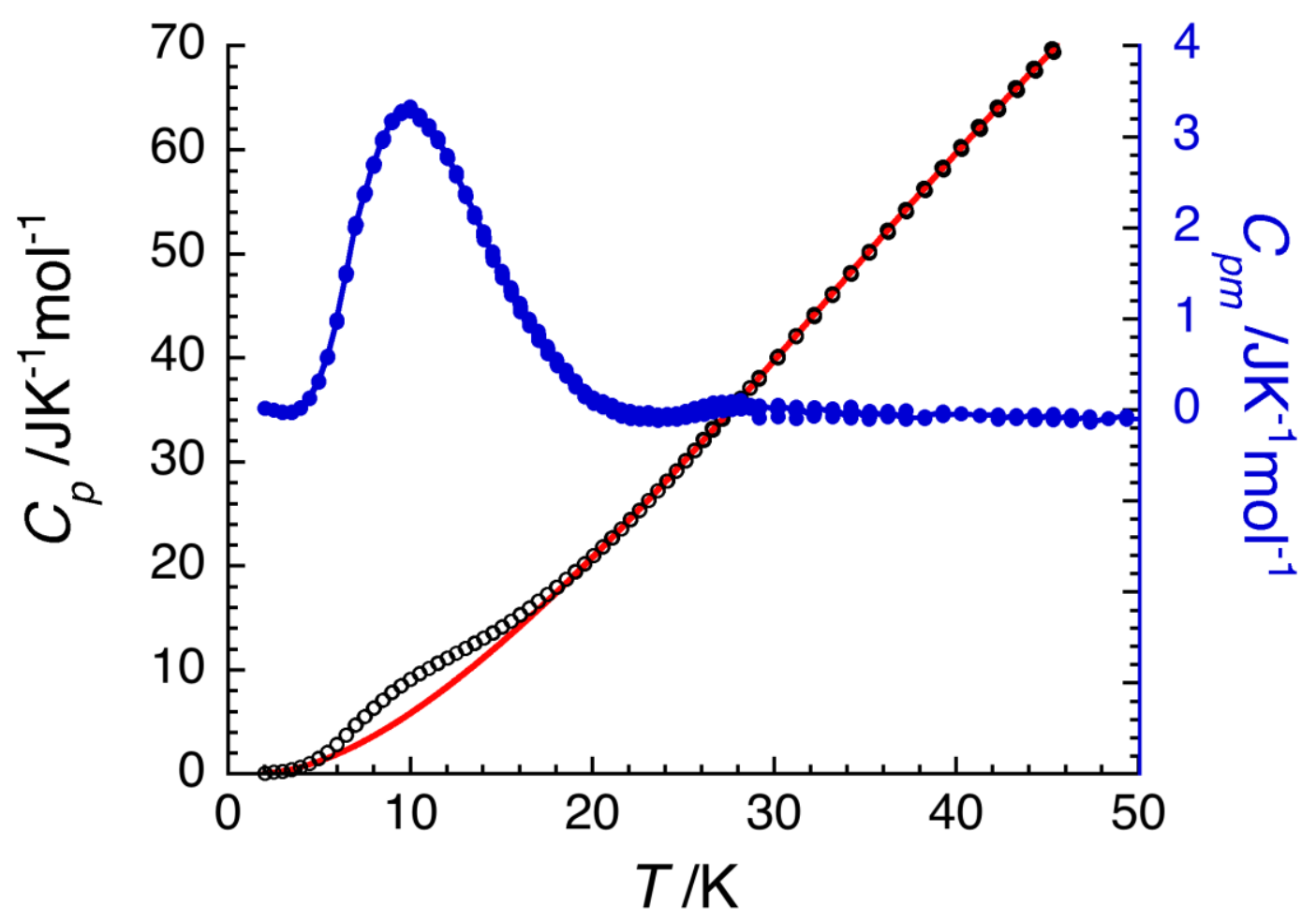

